\title{
Doença mental e consumo nas revistas semanais brasileiras
}

\section{Paulo Vaz ${ }^{1}$}

\section{Resumo}

0 artigo propõe considerar reportagens sobre transtornos mentais publicadas em revistas semanais brasileiras, nos últimos 15 anos, como peças publicitárias para estimular o consumo de medicamentos, especificamente, de antidepressivos. Investiga, então, o nexo entre consumo e subjetividade contemporânea pelo estudo das estratégias retóricas que permitem ao indivíduo se conceber como um possível doente e, assim, consumidor de medicamentos. Duas estratégias são enfatizadas. Uma contorna 0 estigma associado à doença mental por separar 0 sofrimento da moral; a outra analisa o uso de testes como modo de gerar uma incerteza no indivíduo sobre a normalidade de seus estados mentais.

\section{Palavras-Chave}

Mídia. Consumo. Subjetividade. Doença Mental. Antidepressivos.
Paulo Vaz | paulorgvaz@uol.com.br Doutor em Comunicação pela Universidade Federal do Rio de Janeiro (UFRJ). Professor adjunto da Escola de Comunicação da UFRJ.

\section{Consumo, mídia e subjetividade}

0 capitalismo global, desde a década de 60 do século passado, passou a sublinhar 0 desenvolvimento de estratégias para dar forma à demanda. Acompanhando essa mudança de ênfase da produção ao consumo, os estudos que visam identificar as forças de regulação social e os mecanismos de formação de identidade deslocaram seu foco da produção de trabalhadores disciplinados para a constituição de "bons" consumidores, aqueles capazes de sustentar por muito tempo uma demanda sempre crescente e diversificada de mercadorias.

A análise de peças publicitárias constitui um caminho bem explorado por estudiosos de mídia para pensar como os meios de comunicação participam da regulação social através da produção de subjetividade. Essas peças costumam utilizar mecanismos de identificação entre os personagens e a audiência, propondo a cada um de nós, o que é possível ser. Num comercial qualquer que passe na TV, vemos uma personalidade endossando um determinado 
produto. Para a produção de subjetividade, não importa tanto se consumiremos ou não aquela mercadoria; importa, sim, o reconhecimento tácito do valor do modo de vida corporificado naquele que endossa. Como se costumava dizer, a questão do indivíduo em relação à mercadoria não é ter, mas ser: 0 que ele imagina se tornar ao possuí-la, o que implica em já aceitar como desejável o modo de ser representado pela personalidade.

Além da identificação, uma peça publicitária também participa da produção de subjetividade porque quer nos ensinar o que deve ser a vida se quisermos bem vivê-la. Ao expor um produto, também expõe valores que tornam, senão desejável, ao menos razoável o consumo. No início desse século, uma companhia de cartão de crédito fez diversas peças publicitárias com o lema "porque a vida é agora”. Slogan certamente adequado a uma companhia de cartão de crédito, pois seu uso implica materialmente empenhar o futuro tendo em vista a possibilidade de um prazer no presente.

Mas que também sugere que 0 tempo de nossas vidas, aquele entre nosso nascimento e morte, é constituído de oportunidades únicas. A sabedoria consiste então em reconhecê-las e aproveitá-las quando se apresentam. Nessa compreensão da vida, 0 arrependimento que devemos temer nos atormentar no futuro não é 0 de ter feito hoje 0 que a moral tradicional nos diz que ninguém deve fazer e, sim, o de nada ter feito, de não ter aproveitado a vida enquanto havia tempo.
Este artigo quer explorar um caminho diferente para se pensar a relação entre mídia, consumo, publicidade e produção de subjetividade - 0 jornalismo científico. Mais precisamente, 0 artigo considera como propagandas reportagens articulando a presumida disseminação de doenças mentais entre os brasileiros e a existência de medicamentos - no caso estudado, os antidepressivos - capazes de propiciar aos doentes, senão a cura, ao menos a possibilidade de controle dos seus sofrimentos.

À primeira vista, nada seria mais distante de uma peça publicitária do que uma reportagem sobre a existência de um mal social - 0 crescente número de drogados, a extensão do stress dadas as condições da vida moderna etc. - e as possibilidades de ação coletiva e individual. Uma quer nos induzir a consumir um objeto; a outra nos alertar para a extensão de um problema e indicar os meios de enfrentá-lo.

Essa distância aparente é, de fato, a ocasião para diversificar os estudos sobre como os meios de comunicação produzem subjetividade. 0 fato de as notícias sobre a disseminação de transtornos mentais poderem ser vistas como peças publicitárias - incitariam leitores e espectadores a se conceberem como doente e, assim, a consumirem medicamentos - permite colocar algumas questões sobre 0 indivíduo contemporâneo. Primeiro, em que sentido 
e como uma reportagem sobre uma doença mental endereça seu leitor como um possível consumidor, isto é, como um doente? E por que esse endereçamento não seria imediatamente recusado? Em outras palavras, que estatuto deve ter a doença mental para que seja aceitável se conceber como doente?

Uma análise rápida das características do mercado para alguns produtos da indústria farmacêutica indicará as condições para que seja plausível conceber uma reportagem como peça publicitária, isto é, que, em alguns casos, não há uma oposição simples entre jornalismo, preocupado com a verdade, e publicidade, preocupada com a sedução e 0 estímulo do desejo. Ao mesmo tempo, aparecerão as razões do interesse sobre essas reportagens como mecanismos de produção de subjetividade. Se uma peça publicitária precisa difundir e defender valores que tornam desejável o consumo de produtos, as reportagens sobre medicamentos para dores psíquicas nos indicarão como nossa cultura propõe aos indivíduos lidar com seus sofrimentos. Este estudo complementa, portanto, a análise de propagandas que indicam ao indivíduo o que devem fazer para serem felizes.

\section{0 mercado de medicamentos com receita}

Desde os anos 1970, a indústria farmacêutica é uma das que mais cresce no mundo. Esse dinamismo se reflete na presença de companhias farmacêuticas nos rankings anuais. A revista Forbes, em 2011, classificava

13 empresas farmacêuticas entre as 500 maiores. Para comparar, nessa mesma lista, havia 14 empresas de informática (hardware, software, serviços de internet como a Google e as lojas virtuais), 14 companhias automobilísticas e duas companhias aéreas.

As características do mercado de medicamentos explica a relativa obscuridade de suas estratégias de marketing. Primeiro, o medicamento tem um mercado controlado. A entrada de um novo produto depende de autorização pela autoridade sanitária de um país e, tipicamente, um novo princípio ativo deve passar por uma série de testes até poder ser consumido pelos indivíduos. Adicionalmente, a maior parte dos medicamentos protegidos por patentes requer receita médica para seu consumo. 0s economistas caracterizam o mercado de medicamentos sob receita como um mercado imperfeito: quem irá consumir 0 produto não decide sobre a ocasião do consumo e, dependendo do modo como funciona a saúde pública no país, o consumidor tampouco é quem despende recursos, pois os medicamentos podem ser comprados ou reembolsados pelo Estado. Por mais que 0 indivíduo goste da experiência com o remédio, o consumo efetivo poderá depender da autorização do médico e do plano público de saúde: suas escolhas são limitadas.

Dada essas características, como uma empresa farmacêutica pode moldar a demanda para uma dada substância patenteada? 0s analistas de 
marketing operam com uma diferença temporal básica entre criar um mercado e competir num mercado já criado (APPLBAUM, 2006). Antes de a Coca e a Pepsi competirem, é preciso que já exista um mercado para refrigerantes, isto é, para bebidas doces, não-alcóolicas, gaseificadas e que substituem a água. Posto desse modo, percebemos como foi preciso tempo para os indivíduos se acostumarem com a ideia de beber um refrigerante quando estavam com sede. No caso de um medicamento, criar o mercado significa, muito concretamente, criar a doença.

0 caso mais comentado de criação de um mercado foi o Viagra. Após sua descoberta casual, como efeito colateral de um medicamento para doenças cardiovasculares, o desafio era fazer existir uma doença que correspondesse ao efeito. Havia a dificuldade de ereção, mas esta era vista como fazendo parte do processo natural de envelhecimento. Fazer da dificuldade uma doença, a disfunção erétil, significou descolar o normal do natural. Indivíduos que, antes, se pensavam como envelhecendo passaram a se conceber como doentes e, assim, como podendo e devendo usar um medicamento, um objeto técnico.

De fato, a justificativa de uma intervenção médica é tipicamente a de restabelecer a normalidade. Uma cirurgia estética é considerada aceitável se for corretiva, mas moralmente suspeita se for simplesmente para um indivíduo se adequar a padrões de beleza. A legitimidade de uma intervenção consiste no restabelecimento da normalidade, o qual foi durante muito tempo considerado como o retorno ao natural. Com o Viagra e outros medicamentos, como a terapia de reposição hormonal, os processos naturais não são mais a âncora da normalidade; ou ainda, o "natural" se torna um estado de felicidade do indivíduo.

Após o mercado ser criado e a demanda se estabilizar, como é possível aumentá-la? Uma primeira estratégia é ir para outros países; processo que pode equivaler a criação de um mercado se o país-alvo tiver uma cultura bastante diferente. Uma segunda estratégia é propor que o medicamento funciona para outras doenças, o que também implica a estratégia adicional de assegurar a existência dessas outras doenças; veremos que os antidepressivos passaram a ser prescritos para tensão prémenstrual, obesidade, dores físicas (fibromialgia, enxaqueca etc.) e outras doenças mentais, como transtorno obsessivo-compulsivo e fobias, em princípio bastante diferentes da depressão, pois, ao invés de implicarem uma baixa geral do humor, implicam ansiedade e angústia e, portanto, aumento de tensão.

Uma terceira estratégia para aumentar a demanda é agir sobre aqueles que prescrevem, os médicos. 0 caminho pode ser ampliar o número daqueles que estão capacitados a receitar um medicamento; por exemplo, os laboratórios podem combater a crença de que apenas os psiquiatras estão aptos a receitar antidepressivos ou podem criar 
procedimentos que facilitem o diagnóstico de depressão pelo não-especialista. Na Austrália, as empresas farmacêuticas financiaram a criação de um teste diagnóstico simples para a depressão, cujo preenchimento demoraria apenas cinco minutos, para ser aplicado em consultórios de clínicos gerais - como resultado adicional, cerca de metade dos pacientes que respondiam às perguntas se descobriu com depressão (MOYNIHAN; CASSELS, 2005).

A estratégia mais utilizada, porém, é solidificar 0 relacionamento de dom e contra-dom entre médicos e representantes comerciais. Esse relacionamento pode se limitar ao fornecimento de amostras grátis; mas pode incluir o financiamento de congressos (apadrinhar sessões, pagar passagens e hotel etc.) e da atividade científica, de modo geral. Com o avanço nas técnicas de construção de bancos de dados, as empresas podem ainda testar a fidelidade dos médicos e a efetividade de seus representantes comerciais. Um conhecido psiquiatra argentino pediu ajuda financeira a uma empresa farmacêutica para a publicação da revista científica que editava; qual não foi sua surpresa ao saber da razão da recusa dada pelo gerente: a empresa sabia que 0 psiquiatra só receitava antidepressivos de seus concorrentes (LAKOFF, 2006). 0 laboratório sabia do comportamento do psiquiatra porque existem empresas que constroem bancos de dados por fotocopiarem as receitas apresentadas pelos consumidores nas farmácias; assim, é possível saber quem prescreve o quê para qual doença.
Uma última estratégia para aumentar a demanda é agir diretamente sobre 0 indivíduo, fazendo com que ele se conceba como doente em potencial, isto é, criando meios para que ele se diagnostique e vá consultar um médico para confirmar seu sofrimento e o meio de cura. Eis o desafio nesse caso: fazer com que o indivíduo se pense como vulnerável, como em risco, e que o perigo de estar nessa condição é grande o suficiente para que ele procure ajuda. Uma dificuldade dessa estratégia é que, na maior parte dos países, é proibida a publicidade direta ao consumidor de medicamentos que exigem receita médica. É nesse lugar que os especialistas de marketing poderão recorrer a reportagens: 0 "jornalismo científico" é um dos modos de contornar a restrição à publicidade direta.

0 que deve ser uma reportagem sobre uma doença e as possibilidades de intervenção médica para que ela possa funcionar como uma peça publicitária? Nos Estados Unidos, não há restrição à publicidade direta. Uma propaganda de 2002 é particularmente interessante; ela quer persuadir os telespectadores que o Paxil, um antidepressivo, seria eficaz para 0 Transtorno de Ansiedade Generalizado, uma doença mental que não é reconhecida oficialmente pela Associação Psiquiátrica Americana, a instituição responsável pela publicação do Diagnostic and Statistical Manual of Mental Disorders (DSM), o mais famoso manual a listar as doenças mentais e seus sintomas. A peça publicitária combina, portanto, três estratégias de marketing que foram 
analiticamente diferenciadas: criar uma nova doença; afirmar a eficácia do medicamento para outras doenças; criar técnicas para sugerir ao indivíduo que ele pode estar doente.

A propaganda, com o slogan "Paxil... sua vida está esperando", quer persuadir o "consumidor" que sua ansiedade no dia-a-dia, em casa e no trabalho, acontecia, não porque ele estava preocupado e a preocupação é comum à existência humana, mas, sim, que ele estava sofrendo de um transtorno tratável (ROSE, 2006). Quatro pessoas, dois homens e duas mulheres, descrevem o que sentem: "Eu sempre acho que alguma coisa terrível vai acontecer e não consigo controlar isso" ou "É como se eu nunca tivesse a chance de relaxar. No trabalho, estou preocupado com as tarefas de casa.

Em casa, estou preocupado com as coisas do trabalho". Em seguida, uma voz feminina em off: "Se você é uma das milhões de pessoas que vivem com preocupação e ansiedade incontroláveis, ou com vários desses sintomas (os sintomas aparecem na tela enquanto ela fala: preocupação - ansiedade - tensão muscular cansaço - irritabilidade - falta de concentração - distúrbios no sono), você pode estar sofrendo de Transtorno de Ansiedade Generalizado e um desequilíbrio químico pode ser o culpado. Paxil atua para corrigir esse desequilíbrio e aliviar a ansiedade". No final do anúncio, as mesmas pessoas que se queixavam no início estão felizes, rindo, brincando com crianças e lavando carros. Uma delas diz a frase final: "Eu não estou mais tomada pela preocupação; sinto como se fosse eu mesma de novo" (ROSE, 2006, p. 213-214).

As imagens significando a vida feliz se parecem com aquelas em comerciais de carros, celulares, bebidas, ou produtos de limpeza: o indivíduo sorrindo na companhia do cônjuge ou filhos ou amigos. Assim, também é semelhante a normatividade dos estados de felicidade individuais; uma vez mais, a cura, diz a face sorridente, implica sentir-se como si mesmo novamente. A singularidade consiste na presença de três elementos: a proposição de uma doença que, presumidamente, atinge a muitos; mecanismos retóricos para que 0 indivíduo se conceba como doente em potencial; e o retorno à felicidade aberto pelo objeto técnico.

\section{As maravilhas da serotonina}

Para construir 0 corpus, foi feita inicialmente uma pesquisa com a palavra-chave "Serotonina" no acervo digital da revista Veja. Limitar a pesquisa a esse termo tem uma razão maior: é elemento decisivo de todas as estratégias para a venda de antidepressivos a suposição de um nexo causal entre uma doença mental e a redução do nível de serotonina no cérebro - como diz o comercial do Paxil, um desequilíbrio químico pode ser 0 responsável. Assim, essa busca, ao mesmo tempo em que eliminava todas as reportagens onde a depressão não estava associada à serotonina, incluía necessariamente aquelas onde 0 
antidepressivo era recomendado para outros sofrimentos e transtornos.

0 resultado inicial foi de 86 reportagens, a primeira em 1983. Pelo fato de 0 Prozac ter começado a ser vendido no final da década de 1980 nos Estados Unidos e no início da década de 1990 no Brasil, era esperada uma concentração temporal dos resultados: efetivamente, foram publicadas 77 reportagens entre 1995 e 2011, cerca de $90 \%$ do total. Após uma primeira leitura, foram aplicados dois critérios adicionais de restrição: as reportagens deveriam ou tratar dos efeitos dos antidepressivos, ou ter a forma básica das peças publicitárias: doença mental disseminada, procedimentos induzindo 0 autodiagnóstico e a esperança trazida pelo medicamento. Ficaram, então, 20 reportagens publicadas entre 1997 e 2011.

Para saber se 0 corpus estava enviesado por basear-se apenas numa revista, foi repetida a pesquisa com a palavra-chave nos sítios das duas outras grandes revistas semanais brasileiras, as revistas Época e IstoÉ. Para comparar, foram selecionadas três reportagens da $I s t o E ́$ e duas da Época.

Uma reportagem da IstoÉ, de 2004, tratava da síndrome do pânico. Após informar ao leitor da prevalência da doença (em números absolutos, 3 milhões e 500 mil, e não relativo, pois seria pouco mais de $2 \%$ ) e descrever 0 horror de seus sintomas, a reportagem afirma que "felizmente, a ciência tem feito um grande esforço para trazer alívio para essas pessoas" (CÔRTES; ZACHÉ, 2004). Pelo esforço, teriam sido descobertas a mudança na química cerebral - desequilíbrio na produção e absorção da serotonina e da noradrenalina - e a solução dada pelos medicamentos que inibem a recaptura da serotonina, isto é, os antidepressivos.

Em 2003, a reportagem intitulada Traídos pelo desejo incluía dois elementos das estratégias de marketing: além de propor, como na reportagem sobre a síndrome do pânico, a eficácia dos antidepressivos para outras doenças que não a depressão, agora se afirmava a existência de transtornos mentais ainda não reconhecidos oficialmente pela associação norte-americana de psiquiatria, - American Psychological Association (APA), ou a Organização Mundial de Saúde (OMS), como a compulsão ao sexo, às compras, ao uso da Internet ou à prática de exercícios físicos. Após lermos alguns depoimentos de vítimas dessas compulsões, seremos informados de que também "há uma boa notícia": graças à terapia comportamental aliada ao uso de antidepressivos, os sintomas podiam ser controlados, melhorando a qualidade de vida dos compulsivos (TARANTINO; ZACHÉ, 2003).

A terceira reportagem na revista $I s t o E ́$ selecionada é de 2006 e trata da Tensão Pré-Menstrual (TPM). Uma vez mais, após a vívida descrição dos sofrimentos causados pela "doença", há uma "boa notícia”, que nos remete a desequilíbrios químicos 
e a efetividade dos antidepressivos em controlá-lo (CASTELLÓN, 2008).

A revista Época, por sua vez, em 2003 e 2004, publicou duas reportagens de capa sobre a depressão. A primeira, intitulada Os desafios da depressão, afirma logo no início que a depressão é um dos maiores problemas mundiais de saúde pública. Na sequência, repetindo a frase que apareceu na IstoÉ, afirma também que há uma boa notícia: a depressão tem cura, desde que descoberta cedo e tratada adequadamente, 0 que requer 0 uso de antidepressivos (VEIGA; BURCKHARDT, 2003). Ao longo do texto, aparecem depoimentos de celebridades e pessoas comuns sobre as experiências da doença e de ser medicada - aliás, ninguém melhorou sem o medicamento -, assim como há um boxe com um questionário cujo preenchimento permitirá ao indivíduo determinar se está ou não doente. A segunda reportagem, praticamente um ano depois, tem seu conteúdo resumido pelo título: Os herdeiros do Prozac. A leitura nos assegura sobre os inúmeros benefícios trazidos pelos novos antidepressivos "descobertos" pela indústria farmacêutica, além de trazer depoimentos tocantes e um boxe com outro teste para facilitar o autodiagnóstico (VEIGA, 2004).

0 breve exame das reportagens sobre antidepressivos nas revistas Época e IstoÉ mostrou semelhanças de forma e conteúdo com as reportagens da revista Veja. Pelas semelhanças, é plausível supor que as empresas farmacêuticas, até pela experiência com o mercado de outros países, empreguem profissionais de mídia experientes e conhecidos, capazes de produzir excelentes releases ou sugerir temas a colegas. De fato, frases e especialistas se repetem ao longo dos anos; reportagens com temas idênticos aparecem no mesma semana, como as de maio de 2004 na Veja e na Época, anunciando a chegada em breve da Duloxetina, princípio ativo do medicamento Cymbalta fabricado pelo laboratório Eli Lilly, que lançou o Prozac.

Em relação à revista Veja, apenas uma reportagem em todo o corpus é claramente crítica. Publicada em 1997 com o título O Brasil se entope de remédio, apresenta diversos casos de consumo excessivo de medicamentos, um deles sendo 0 consumo de antidepressivos. Diz a reportagem: "a classe média adotou outros hábitos não tão saudáveis, como consumir antidepressivos à moda dos americanos" (FRANÇA, 1997, p. 77).

0 restante das reportagens apresenta positivamente 0 consumo de medicamentos. De fato, há duas com a função de defender a indústria farmacêutica. Em 2004, o Food and Drug Administration (FDA), órgão responsável, dentre outras funções, pelo licenciamento de remédios, recomendou a suspensão do uso de antidepressivos em crianças e adolescentes, pois tinha havido casos de suicídio que poderiam estar associados ao uso do medicamento. A revista sugere que o FDA só recomendou a suspensão por preocupação, quase como se fosse uma questão 
de aversão ao risco, pois "não existe nenhuma evidência científica de que os antidepressivos possam estar relacionados às mortes" (BUCHALLA, 2004, p. 65).

Em 2008, foi lançado um livro onde um cientista norte-americano afirma que não há praticamente diferença no tratamento da depressão entre antidepressivos e placebo. A revista, então, numa reportagem intitulada $A$ depressão em preto e branco, diz que todos os especialistas brasileiros que ouviu acreditam haver uma diferença. Cabe ressaltar que a revista não explicitou seus critérios para atribuir a cientistas 0 estatuto de especialistas. Num boxe, apareceu também um argumento curioso, sugerindo que a semelhança de efeito com um placebo não desqualificaria 0 medicamento: "se o placebo funciona, isso não significa que um antidepressivo não funciona" (MAGALHÃES; MACEDO, 2010, p. 78). Não é mencionado que há uma diferença de custo, seja ele o preço, seja ele 0 efeito colateral, entre a pílula de farinha e um antidepressivo.

Outras reportagens pareciam ter como razão de ser o surgimento de um novo medicamento, adotando tipicamente uma narrativa de progresso e, assim, discutindo seus méritos relativamente aos remédios que já estavam no mercado. Reportagens, portanto, que deixavam a sensação de serem meras propagandas a influir na preferência dos indivíduos entre os antidepressivos.
As reportagens que mais interessam teoricamente são aquelas que nos permitem pensar o processo de produção de subjetividade. Podem ser reportagens de capa e seu foco é a associação entre a disseminação de um transtorno mental e a possibilidade de intervenção terapêutica. Duas reportagens tratam especificamente da depressão. A primeira, publicada em 1999, foi uma reportagem especial e intitulava-se $A$ doença $d a$ alma. A segunda, de 2003, intitulada A tristeza do macho, se propunha a dar outra interpretação para o dado epidemiológico de que há o dobro de mulheres atingidas pela depressão do que homens. A explicação para a diferença não era biológica, mas social: a depressão atingia igualmente os sexos, mas os homens não tinham a coragem de se reconhecer como doentes, pois estavam dominados pelo preconceito social de haver valor em suportar o sofrimento.

As outras reportagens exemplificaram a estratégia de marketing "ampliar a demanda por se apresentar como efetivo para outras doenças". Eis os casos: Emoção e saúde, para doenças psicossomáticas; Muita calma nessa hora... e Transtorno de sobra, que tratavam da TPM; Medo além da conta, sobre fobias; Novas armas contra $a$ dor, onde os medicamentos seriam efetivos para lidar com as dores crônicas, como enxaqueca e fibromialgia; $A$ mais comum das dores, que trata dos diferentes tipos de dor de cabeça; e Mentes que aprisionam, sobre diversos tipos de transtornos obsessivo-compulsivos. Somatizações, fobias, obsessões - os inibidores da retomada 
de serotonina ambicionam 0 vasto território anteriormente ocupado pelos psicanalistas e seus neuróticos.

\section{As estratégias de produção de subjetividade}

\author{
A forma genérica dessas reportagens é \\ "problema social grave com solução técnica". \\ A reportagem $A$ doença da alma resume essa \\ forma em poucas linhas:
}

Cerca de 330 milhões de pessoas de ambos os sexos no mundo inteiro padecem desse tipo de sofrimento profundo. São dois Brasis de vítimas de todas as idades, classes sociais e raças, mergulhadas numa melancolia atroz que altera seus hábitos de vida, afastando-as do convívio social e do trabalho. Antes que se imagine um planeta mergulhado numa nuvem negra de habitantes depressivos e sem esperança, é bom saber que o tratamento eficaz da depressão nunca esteve tão próximo e acessível (CARDOS0; LUZ, 1999, p. 95-96).

As reportagens tratam, portanto, de doenças amplamente disseminadas pela sociedade, mas que, curiosamente, apesar da disseminação, doenças cuja gravidade ninguém conhece. A conjunção entre ignorância e disseminação só é logicamente possível se é suposto um alto número de falsos negativos; ou ainda, se as vítimas ou não sabem que estão doentes, ou têm vergonha de dizer aos outros a sua enfermidade. No caso das reportagens, 0 argumento será que o preconceito em relação à doença mental induz os indivíduos a não saberem ou a não reconhecerem que estão doentes. A reportagem especial sobre depressão é novamente exemplar: "a grande maioria dos deprimidos passa a vida sofrendo e morre sem ter uma ideia precisa sobre 0 tipo de doença de que foi vítima - e sem procurar tratamento médico. Nove em cada dez pessoas afetadas pela depressão não sabem que têm uma moléstia específica." (CARDOS0; LUZ, 1999, p. 96). Se há $90 \%$ de falsos negativos, quem sabe se 0 leitor, que anda entristecido, não está doente sem 0 saber?

Cabe então à revista remover os obstáculos, morais e cognitivos, ao reconhecimento de si como possível doente. 0 estigma em relação às doenças mentais está associado ao nexo entre sofrimento e moralidade, próprio da cultura ocidental porque associado ao surgimento da figura do sujeito e que só em nossa atualidade parece entrar em crise. 0 sujeito emerge pela ilusão de controle da consciência do indivíduo sobre uma parte dele mesmo e, graças a esse controle, sobre os eventos que podem vir a lhe ocorrer. Através da ação do indivíduo sobre uma parte de si mesmo, o futuro se tornaria passível de ser conhecido, calculado e dependente da ação do indivíduo sobre si mesmo. É parte integrante da experiência de se sentir culpado a expectativa de uma punição. Essa relação temporal entre presente e futuro pode ser deslocada para o nexo entre presente e passado como forma de explicar os sofrimentos atuais. Se sofro agora, é porque agi imoralmente no passado; para não sofrer, é preciso não ceder às tentações, controlar os prazeres do corpo. 
Concretamente, essa relação entre sofrimento e moralidade faria da doença mental ou uma imoralidade ou o castigo por uma imoralidade prévia - cabe lembrar que os doentes mentais, na sociedade moderna, eram aparentados aos criminosos e aos perversos sexuais. $\mathrm{Na}$ origem de uma doença mental, estaria alguma imoralidade. Por outro lado, o sofrimento voluntariamente dado a si ou é condição de cura, tratamento, ou é sacrifício necessário para qualquer realização. Como é uma relação ordenada pela ideia de equivalência, quanto maior o feito, mais profundo deveria ser 0 sofrimento. A genialidade teria a melancolia como condição.

As reportagens desenvolverão argumentos questionando esse nexo entre sofrimento e moral. Inicialmente, proporão que um comportamento anteriormente visto como imoralidade é, de fato, doença. Trata-se do movimento básico de medicalização; no caso mais estudado, o homossexual não seria um pecador e, sim, um doente. Do mesmo modo, o comportamento errático e agressivo de mulheres um pouco antes de menstruarem seria doença e não falha moral (BUCHALLA; NEIVA, 2007); o fato de indivíduos não conseguirem trabalhar pode não ser preguiça, mas depressão (ZAKABI, 2003); a dependência de álcool ou drogas pode ser doença causada pela baixa autoestima dos indivíduos com manias etc. (NEIVA; PASTORE, 2004) Em suma, cabe diagnosticar e tratar, ao invés de julgar e punir.
0 mais importante para a produção de subjetividade são os novos argumentos que visam desconectar o sofrimento da moral. Eis alguns: 0 tratamento das doenças mentais antes parecia uma punição, pelo internamento e pelo prognóstico sombrio (ZAKABI, 2003); se um escritor que, supostamente, sofreu de depressão, como Hemingway, tivesse tido a oportunidade de se medicar, teria escrito mais e melhores livros (CARDOSO; LUZ, 1999); reconhecer-se como sofrendo de depressão requeria coragem, pois o preconceito moral associado à masculinidade conduz os homens a crerem que é fraqueza não suportar a tristeza (ZAKABI, 2003); a dor é um problema em si mesma, de tal modo que combatêla é um alvo legítimo e não uma forma de mascarar a doença que a originou (BUCHALLA; POLES, 2002).

0 outro obstáculo a se conceber como doente é o desconhecimento de fatores de risco e de sintomas da doença. Duas estratégias retóricas se destacam. Uma é o depoimento de celebridades e pessoas comuns; por apresentarem os sintomas numa linguagem simples, sem termos técnicos, permite ao indivíduo objetivar suas emoções, mas na proximidade da patologia. A segunda é 0 teste, com questões simples a serem respondidas quantitativamente, de modo que o somatório das respostas define o limiar da doença. Este é um dispositivo eficaz porque, em primeiro lugar, estamos acostumados a responder a testes para nos identificar e educar. Revistas femininas e de adolescentes costumam propor testes para 
sabermos o tipo de namorado ou amigo que somos. É fácil saber qual é a "boa" resposta e, portanto, responder para descobrir-se sendo 0 que se queria ser, ao mesmo tempo em que se aprende 0 que fazer.

No caso dos testes sobre doença mental, a identificação é negativa, isto é, o indivíduo não quer se conceber como deprimido, fóbico, compulsivo etc. A estratégia retórica consiste, então, em impossibilitar 0 estabelecimento de uma distância segura em relação à possível doença. Nos testes, os indivíduos são incitados a avaliar sua sanidade por qualificar seus estados mentais; uma emoção é para ser descrita segundo uma intensidade ou frequência. Para saber se tenho uma simples mania ou um ritual compulsivo, tenho que determinar, por exemplo, o quanto temo ser contaminado ou se o tempo que demoro para sair de casa é adequado ou excessivo (NEIVA; PASTORE, 2004); para a TPM, uma mulher tem que decidir se sua ansiedade e irritabilidade são pouco ou muito intensas (BUCHALLA; NEIVA, 2007); em relação às dores crônicas, os indivíduos devem alocá-las numa escala de quatro níveis (BUCHALLA: POLES, 2002); para as fobias, os indivíduos devem saber se são ou não perfeccionistas, se têm um senso de responsabilidade excessivo etc. (MARI, 1999).

Sabemos que é impossível um acesso imediato à mente do outro. Como posso saber então se meu medo ou tristeza são adequados, excessivos ou insuficientes, se não tenho como comparar o que está em minha mente com o que está na mente do outro? A forma contemporânea de caracterizar as doenças mentais, hegemônica desde a década de 80 do século passado, permite essa proliferação de testes, pois é baseada numa lista de sintomas. Pela experiência com os depoimentos e comportamentos, por fazer a comparação entre pacientes e não de si com os outros, talvez um psiquiatra seja capaz de saber se alguém está ou não deprimido a partir de uma lista apontando desvios em emoções e comportamentos cotidianos. Para 0 autodiagnóstico, porém, 0 teste significa um novo modo de aprender o sentido dos termos mentais. Incapazes de compararmos o que experimentamos com o que os outros experimentam e convidados a nos inquietarmos com o excesso ou insuficiência do que sentimos, só nos resta fantasiar nossa possível patologia e procurar o conselho de especialistas.

\section{A efetividade das reportagens}

Uma questão a ser colocada é sobre a efetividade dessas reportagens. Afinal, são poucas; na VEJA, cerca de cinco por ano. Uma medida de efetividade é 0 sucesso comercial. A reportagem $A$ depressão em preto e branco cita dados sobre o consumo de antidepressivos no Brasil produzidos pela IMS Health, uma empresa especializada em fornecer informações para os laboratórios farmacêuticos. A receita com a venda teria passado de 236 em 2005 para 519 milhões de dólares em 2009 - mais do que dobrou em cinco anos. Embora impressionante, 0 aumento não significa que 
tenha duplicado o número de brasileiros que se diagnosticam e/ou são diagnosticados como deprimidos. Por exemplo, os antidepressivos podem estar substituindo os ansiolíticos.

Uma medida de efetividade mais interessante é 0 estatuto atual da serotonina como objeto importante do cuidado de si. Nas revistas de saúde e nos jornais diários, é comum mencioná-la em relação a alimentos - nutricionistas dizem que banana e chocolate poderiam aumentar o seu nível. Está naturalizada a relação causal, essencial para a estratégia de marketing dos laboratórios, entre nível de serotonina e sensação de bem-estar. Embora essas notícias estejam defendendo uma estratégia preventiva e "natural", via nutrição, para manter um "bom" nível de serotonina, não só está legitimada uma intervenção artificial e curativa em determinadas circunstâncias; está também naturalizada uma compreensão do que é nosso pensamento e do modo de agir sobre ele.

No longo prazo, talvez o que seja mais relevante é 0 esforço dessas estratégias de marketing de desconectar sofrimento da moral. Essa desconexão é uma peça a mais num conjunto de práticos a sustentar a elaboração de uma nova subjetividade. Ao identificar, pela forma de tratamento, o sofrimento psíquico a uma gripe, 0 que se faz, em última instância, é construir uma temporalidade onde 0 arrependimento futuro a ser temido no presente é o de não ter aproveitado as oportunidades quando elas se abriram, onde a dívida gerada pelos prazeres é apenas material, onde é possível o prazer sem custo moral. Ao fazer isso, porém, corre-se o risco de retirar o potencial de questionamento de si tanto do prazer, quanto do sofrimento.

\section{Referências}

APPLBAUM, Kalman. Educating for global mental health. In: PETRYNA, Adriana; LAKOFF, Andrew; KLEINMAN, Arthur (Org.). Global farmaceuticals: ethics, markets, practices. Duke: Duke University Press, 2006. p. 84-109.

BUCHALLA, Anna Paula. A era dos super-remédios. Veja. São Paulo, 26 jun. 2002. n. 1757, p. 94-101. BUCHALLA, Anna Paula. Emoções e saúde. Veja. São Paulo, 05 dez. 2007. n. 2037, p. 161-168.

BUCHALLA, Anna Paula. Mais uma pílula da felicidade. Veja. São Paulo, 05 set. 2001. n. 1716, Saúde, p. 82-4.

BUCHALLA, Anna Paula. Prozac foi só o começo. Veja. São Paulo, 12 mai. 2004. n. 1853, Medicina, p. 65-66.

BUCHALLA, Anna Paula. Sob suspeita. Veja, São Paulo, 31 mar. 2004. n. 1847, Medicina, p. 65-66.

BUCHALLA, Anna Paula; NEIVA, Paula. Muita calma nessa hora... Veja. São Paulo, 06 jun. 2007. n. 2011, Saúde. p. 117-121.

BUCHALLA, Anna Paula; POLES, Cristina. Novas armas contra a dor. Veja. São Paulo, 06 fev. 2002. n. 1737, p. $72-79$.

CARDOSO, Mauricio; LUZ, Sérgio Ruiz. Depressão: a doença da alma. Veja. São Paulo, 31 mar. 1999. n. 1591, p. $94-101$.

CASTELLÓN, Lena. Sob o domínio da TPM. IstoÉ. São Paulo, 02 mai. 2008. n. 2009, Medicina \& Bem-Estar, p. $90-98$.

COLAVITTI, Fernanda. Transtorno de sobra. Veja. São Paulo. 05 set. 2001. n. 1716, Guia, p. 122. 
CÔRTES, Celina; ZACHÉ, Juliane; TARANTINO, Mônica. A sombra do pânico. IstoÉ. São Paulo, 25 ago. 2004. n. 1820 , p. $80-6$

EDWARD, José. Tratamento de choque contra a depressão. Veja. São Paulo, 06 jul. 2005. n. 1912, Guia, p. $98-100$.

FRANÇA, Valéria. 0 Brasil se entope de remédios. Veja. São Paulo, 11 Jun. 1997. n. 1499, Medicina, p. 76-81.

LAKOFF, Andrew. High Contact: gift and surveillance in Argentina. In PETRYNA, Adriana; LAKOFF, Andrew; KLEINMAN, Arthur (Org.). Global farmaceuticals: ethics, markets, practices. Duke: Duke University Press, 2006. p. 110-135.

MAGALHÃES, Naiara; MACEDO, Daniela. A depressão em preto e branco. Veja. São Paulo, 10 fev. 2010. n. 2151, Saúde, p. 78-83.

MARI, Juliana de. Medo além da conta. Veja. São Paulo, 10 nov. 1999. n. 1623, Medicina, p. 146-152.

MING, Laura. A dor da alma dói no corpo. Veja. São Paulo, 06 abr. 2011. n. 2211, Saúde, p. 100-101.

MING, Laura; MORAES, Renata. 0 ponto fraco. Veja. São Paulo, 01 abr. 2009. n. 2106, Medicina, p. 88.

MOYNIHAN, Ray; CASSELS, Alan. Selling sickness. Sydney: Allen \& Unwin, 2005.

NEIVA, Paula; PASTORE, Karina. Quando as manias viram doenças. Veja. São Paulo, 05 mai. 2004. n. 1852, p. 130-139.

OLIVEIRA, Fabio de. Dose semanal - Prozac ganha versão útil em recaída de depressão. Veja. São Paulo, 21 mar 2001. n. 1692, Guia, p. 140.

PASTORE, Karina. A mais comum das dores. Veja. São Paulo, 02 jul. 2003. n. 1809, p. 80-87.

PASTORE, Karina; POLES, Cristina. A cabeça dói... Veja. São Paulo, 02 fev. 2000. n. 1634, Saúde, p. 74-78. ROSE, Nikolas. The politics of life itself: biomedicine, power, and subjectivity in the twenty-first century. New Jersey: Princeton University Press, 2006.

TARANTINO, Monica; ZACHÉ, Juliane. Traídos pelo desejo. IstoÉ. São Paulo, 05 ago. 2003. n. 1766,

Psiquiatria, p. 90-96

VEIGA, Aida. Os herdeiros do prozac. Época. Rio de Janeiro, 10 mai. 2004. n. 12, p. 80-88.

VEIGA, Aida; BURCKHARDT, Eduardo. 0 desafio da depressão. Época. 05 mai. 2003. n. 259, p. 76-84.

ZAKABI, Rosana. A tristeza do macho. Veja. São Paulo, 26 nov. 2003. n. 1830, Saúde, p. 106-108. 


\begin{tabular}{|c|c|}
\hline $\begin{array}{l}\text { Mental Disorder and consumption } \\
\text { in Brazilian weekly magazines }\end{array}$ & $\begin{array}{l}\text { Trastornos mentales y consumo en } \\
\text { semanarios brasileño }\end{array}$ \\
\hline $\begin{array}{l}\text { Abstract } \\
\text { The article proposes to conceive newspieces on } \\
\text { mental disorders published in weekly magazines } \\
\text { as advertisements aimed at stimulating the } \\
\text { consumption of medication, in particular of } \\
\text { antidepressants. It then examines the linkages } \\
\text { between consumption and contemporary } \\
\text { subjectivities by analyzing two main rhetorical } \\
\text { strategies by which individuals may come to } \\
\text { conceive of themselves as possibly ill and thus as } \\
\text { a potential consumer of medication. The first one } \\
\text { separates suffering and morality, thus erasing the } \\
\text { stigma associated to mental disorders; the second } \\
\text { one inquires how quizzes published in these } \\
\text { newspieces may enhance the sense of uncertainty } \\
\text { in individuals regarding one's allegedly normal } \\
\text { mental states. } \\
\text { Keywords } \\
\text { Media. Consumption. Subjectivity. Mental Disorder. } \\
\text { Antidepressant. }\end{array}$ & $\begin{array}{l}\text { Resumen } \\
\text { El artículo propone examinar noticias sobre } \\
\text { trastornos mentales en semanarios brasileño en } \\
\text { los últimos } 15 \text { años como piezas publicitarias } \\
\text { para estimular el consumo de medicamentos, } \\
\text { específicamente, de antidepresivos. Investiga, } \\
\text { entonces, el vínculo entre el consumo y la } \\
\text { subjetividad en el estudio de las estrategias } \\
\text { retóricas contemporáneas que permiten a los } \\
\text { individuos se concebir como posibles enfermos } \\
\text { y, por lo tanto, como consumidores de fármacos. } \\
\text { Dos estrategias están ressaltados. Uno elude } \\
\text { el estigma asociado con la enfermedad mental } \\
\text { separando el sufrimiento de la moral; el otro analiza } \\
\text { como el uso de test son una manera de generar } \\
\text { una incertidumbre en la persona acerca de la } \\
\text { normalidad de sus estados mentales. } \\
\text { Palabras clave } \\
\text { Media. Consumo. Subjetividad. Trastorno Mental. } \\
\text { Antidepresivo. }\end{array}$ \\
\hline
\end{tabular}




\section{Expediente}

A revista E-Compós é a publicação científica em formato eletrônico da Associação Nacional dos Programas de Pós-Graduação em Comunicação (Compós). Lançada em 2004, tem como principal finalidade difundir a produção acadêmica de pesquisadores da área de Comunicação, inseridos em instituições do Brasil e do exterior.
E-COMPÓS I www.e-compos.org.br I E-ISSN 1808-2599

Revista da Associação Nacional dos Programas

de Pós-Graduação em Comunicação.

Brasília, v.15, n.1, jan./abr. 2012.

A identificação das edições, a partir de 2008

passa a ser volume anual com três números.

\section{CONSELHO EDITORIAL}

Afonso Albuquerque, Universidade Federal Fluminense, Brasil Alberto Carlos Augusto Klein, Universidade Estadual de Londrina, Brasil Álvaro Larangeira, Universidade Tuiuti do Paraná, Brasil Ana Carolina Damboriarena Escosteguy, Pontifícia Universidade Católica do Rio Grande do Sul, Brasil

Ana Gruszynski, Universidade Federal do Rio Grande do Sul, Brasil Ana Silvia Lopes Davi Médola, Universidade Estadual Paulista, Brasil André Luiz Martins Lemos, Universidade Federal da Bahia, Brasil Ângela Freire Prysthon, Universidade Federal de Pernambuco, Brasil Angela Cristina Salgueiro Marques, Faculdade Cásper Líbero (São Paulo), Brasil Antônio Fausto Neto, Universidade do Vale do Rio dos Sinos, Brasil Antonio Carlos Hohlfeldt, Pontifícia Universidade Católica do Rio Grande do Sul, Brasil Antonio Roberto Chiachiri Filho, Faculdade Cásper Líbero, Brasil Arthur Autran Franco de Sá Neto, Universidade Federal de São Carlos, Brasil Benjamim Picado, Universidade Federal Fluminense, Brasil César Geraldo Guimarães, Universidade Federal de Minas Gerais, Brasil Cristiane Freitas Gutfreind, Pontifícia Universidade Católica do Rio Grande do Sul, Brasil Denilson Lopes, Universidade Federal do Rio de Janeiro, Brasil Eduardo Peñuela Cañizal, Universidade Paulista, Brasil Eduardo Vicente, Universidade de São Paulo, Brasil Eneus Trindade, Universidade de São Paulo, Brasil Erick Felinto de Oliveira, Universidade do Estado do Rio de Janeiro, Brasil Florence Dravet, Universidade Católica de Brasilia, Brasil Gelson Santana, Universidade Anhembi/Morumbi, Brasil Gislene da Silva, Universidade Federal de Santa Catarina, Brasil Guillermo Orozco Gómez, Universidad de Guadalajara Gustavo Daudt Fischer, Universidade do Vale do Rio dos Sinos, Brasil Hector Ospina, Universidad de Manizales, Colômbia Herom Vargas, Universidade Municipal de São Caetano do Sul, Brasil leda Tucherman, Universidade Federal do Rio de Janeiro, Brasil Inês Vitorino, Universidade Federal do Ceará, Brasil Jnice Caiafa, Universidade Federal do Rio de Janeiro, Brasil Jay David Bolter, Georgia Institute of Technology Jeder Silveira Janotti Junior, Universidade Federal de Pernambuco, Brasil João Freire Filho, Universidade Federal do Rio de Janeiro, Brasil John DH Downing, University of Texas at Austin, Estados Unidos José Afonso da Silva Junior, Universidade Federal de Pernambuco, Brasil
José Carlos Rodrigues, Pontifícia Universidade Católica do Rio de Janeiro, Brasil José Luiz Aidar Prado, Pontifícia Universidade Católica de São Paulo, Brasil José Luiz Warren Jardim Gomes Braga, Universidade do Vale do Rio dos Sinos, Brasil Juremir Machado da Silva, Pontifícia Universidade Católica do Rio Grande do Sul, Brasil Laan Mendes Barros, Universidade Metodista de São Paulo, Brasil Lance Strate, Fordham University, USA, Estados Unidos Lorraine Leu, University of Bristol, Grã-Bretanha Lucia Leão, Pontifícia Universidade Católica de São Paulo, Brasil Malena Segura Contrera, Universidade Paulista, Brasil Márcio de Vasconcellos Serelle, Pontifícia Universidade Católica de Minas Gerais, Brasil Maria Aparecida Baccega, Universidade de São Paulo e Escola Superior de Propaganda e Marketing, Brasil Maria das Graças Pinto Coelho, Universidade Federal do Rio Grande do Norte, Brasil Maria Immacolata Vassallo de Lopes, Universidade de São Paulo, Brasil Maria Luiza Martins de Mendonça, Universidade Federal de Goiás, Brasil Mauro de Souza Ventura, Universidade Estadual Paulista, Brasil Mauro Pereira Porto, Tulane University, Estados Unidos Mirna Feitoza Pereira, Universidade Federal do Amazonas, Brasil Nilda Aparecida Jacks, Universidade Federal do Rio Grande do Sul, Brasil Paulo Roberto Gibaldi Vaz, Universidade Federal do Rio de Janeiro, Brasil Potiguara Mendes Silveira Jr, Universidade Federal de Juiz de Fora, Brasil Renato Cordeiro Gomes, Pontifícia Universidade Católica do Rio de Janeiro, Brasil Robert K Logan, University of Toronto, Canadá

Ronaldo George Helal, Universidade do Estado do Rio de Janeiro, Brasil Rose Melo Rocha, Escola Superior de Propaganda e Marketing, Brasil Rossana Reguillo, Instituto de Estudos Superiores do Ocidente, Mexico Rousiley Celi Moreira Maia, Universidade Federal de Minas Gerais, Brasil Sebastião Carlos de Morais Squirra, Universidade Metodista de São Paulo, Brasil Sebastião Guilherme Albano da Costa, Universidade Federal do Rio Grande do Norte, Brasil

Simone Maria Andrade Pereira de Sá, Universidade Federal Fluminense, Brasil Tiago Quiroga Fausto Neto, Universidade de Brasília, Brasil

Suzete Venturelli, Universidade de Brasilia, Brasil Valério Cruz Brittos, Universidade do Vale do Rio dos Sinos, Brasil Valerio Fuenzalida Fernández, Puc-Chile, Chile Veneza Mayora Ronsini, Universidade Federal de Santa Maria, Brasil Vera Regina Veiga França, Universidade Federal de Minas Gerais, Brasil

\section{COMISSÃO EDITORIAL}

Adriana Braga I Pontifícia Universidade Católica do Rio de Janeiro, Brasil

Felipe Costa Trotta I Universidade Federal Fluminense, Brasil

CONSULTORES AD HOC

Bruno Campanella, Universidade Federal Fluminense, Brasil

Gisela Grangeiro da Silva Castro, Escola Superior de Propaganda e Marketing, Brasi José Carlos Ribeiro, Universidade Federal da Bahia, Brasil

Luciana Panke, Universidade Federal do Paraná, Brasil

Micael Herschmann, Universidade Federal do Rio de Janeiro, Brasil

Tânia Márcia Cezar Hoff, Escola Superior de Propaganda e Marketing, Brasil

Virginia da Silveira Fonseca, Universidade Federal do Rio Grande do Sul, Brasil

EDIÇÃO DE TEXTO E RESUMOS I Susane Barros

SECRETÁRIA EXECUTIVA I Juliana Depiné

EDITORAÇÃO ELETRÔNICA I Roka Estúdio
COMPós I www.compos.org.br

Associação Nacional dos Programas de Pós-Graduação em Comunicação

Presidente

Julio Pinto

Pontifícia Universidade Católica de Minas Gerais, Brasil

juliopinto@pucminas.br

Vice-presidente

Itania Maria Mota Gomes

Universidade Federal da Bahia, Brasil

itania@ufba.br

Secretária-Geral

Inês Vitorino

Universidade Federal do Ceará, Brasil

inesvict@gmail.com 